\title{
Sexual desire, sexual functioning and well-being in married males: A community based study
}

\author{
G Lakshmana, F Mohd, AB Panda
}

\section{Abstract \\ Background}

Sexual dysfunction is a common yet treatable condition, which is associated with significant negative effects on the quality of life. However the true nature of this problem in India is not known, as many people are hesitant to discuss this topic.

\section{Aims}

The study aimed to measure sexual desire, sexual functioning and well-being among married men in a regional city in India.

\section{Methods}

Fifty-four males were recruited using cluster sampling. Assessments were conducted using the sexual desire inventory, brief sexual functioning inventory and PGIgeneral well-being scales.

\section{Results}

Of the participants, $98 \%$ had a moderate level of overall sexual desire, $81 \%$ reported either mild or moderate sexual dysfunction, $58 \%$ reported moderate problems in ejaculation and $50 \%$ reported moderate problems in erection. $A$ majority (85\%), reported good general well-being. Age was negatively correlated with sexual functioning and sexual desire, whereas general well-being showed a positive correlation.

\section{Conclusions}

Sexual dysfunction is a common problem in Indian males. Increase in awareness about these problems may encourage people to seek treatment for these important health issues.

Key words: sexual function, sexual desire, well-being

SL J Psychiatry 2020; 11(1): 39-44

\section{Introduction}

Sexual functioning is an important part of human life that contributes to quality of life (1). Sexuality has been a consistent focus of curiosity and interest to humankind. Poor sexual health can have a negative impact on general wellbeing, psychological health and relationships (1). Sexual dysfunction refers to a problem occurring during any phase of the sexual response cycle that prevents a person from experiencing satisfaction from the sexual activity (2). The sexual response cycle includes excitement, plateau, orgasm, and resolution. Desire and arousal are part of the excitement phase.

Research suggests that sexual dysfunction is common (2). It is a topic that many people are hesitant to discuss particularly in India, but it is important for health care professionals and policy makers to know about the extent and nature of the problem in the community (2). Our study aimed to assess the level of sexual desire, sexual functioning, subjective well-being and the relationship between these variables in married Indian men.

\section{Methods}

This is a descriptive study, carried out in Kalaburagi, which is a regional city in the Indian state of Karnataka with a total population of 5,43,000, of which $55 \%(2,98$, $650)$ are males $(3,13)$. Three-stage sampling was adopted for the selection of households for inclusion in the study, from within the city population. The primary sampling units (PSUs) were the city wards, secondary sampling units (SSUs) were Census Enumeration Blocks (CEBs), and tertiary sampling units (TSUs) were households. The city wards, and then CEBs from within each selected city ward, were selected randomly. All households within a selected CEB were included in the study. Married males below the age of 45 years, in included households, were invited to take part in the study. Those who reported 
long-term medical disorders, psychiatric disorders and substance addiction were excluded from the study. Out of the 110 respondents approached, 54 men agreed to participate in the study. After obtaining written consent, face-to-face interviews were conducted. Privacy was ensured during the interview process and all efforts were made to guarantee confidentiality. Ethics approval for the study was obtained from the Ethics Review Committee of Central University of Karnataka, India.

\section{The tools used for data collection}

The Sexual Desire Inventory-2 (SDI-2) is a 14-item scale which measures the multi-dimensional construct of sexual desire in a dyadic context (4). The scale has two domains i.e., dyadic sexual desire (9 items) and solitary sexual desire ( 5 items). Total sexual desire can be assessed by summing up of all the items.

The Brief Sexual Function Inventory (BSFI) is an 11-item scale, divided into 5 functional domains namely, sexual drive (3 items), erection (3 items), ejaculation (2 items), problem assessment (3 items) and functional assessment (3 items) (5). Overall satisfaction was also assessed with a single item, and total BSFI was assessed by summing up item scores. Scores were calculated for each of the five domains based on five-point score range from 0 to 4 . The BSFI has been used in previous Indian studies (6-8).

The PGI - General Well-being scale is a 20-item scale, which measures subjective well-being (positive mental health), which has been developed in India (9). The total score of the scale is categorized as poor, moderate and good well-being.
The results were analyzed using the Statistical Package for Social Sciences version 20 (SPSS 20). Descriptive statistics was used to describe the variables. One-way ANOVA was computed to identify any difference in sexual desire, sexual functioning and well-being domains based on the educational qualification, and Pearson's correlation was computed to explore relationships between outcomes of interest and socio-demographic variables.

\section{Results}

The age of the respondents ranged between 26-45 years, with a mean of $33 \pm 4.1$ years. A majority (56\%) of the respondents belonged to the Islamic religion and the remainder were Hindus. In terms of level of education, $41 \%$ had post-graduate qualifications, while $9 \%$ were illiterate. A majority (54\%) were in non-consanguineous marriages and most (90.7\%) reported that their spouses had no health problems.

Based on the results of the sexual desire inventory, almost all respondents reported overall sexual desire to be moderate (Table 1 ). The total BSFI score revealed that only $19 \%$ had good sexual function (Table 2). Overall well-being as per the PGI-General Well-being score showed that $85 \%$ and $15 \%$ had good and moderate wellbeing, respectively. One-way ANOVA indicated a significant difference in the dyadic sexual desire score $(\mathrm{p}<0.05)$ according to educational qualifications (Table 3 ). Increased educational qualification was associated with increased dyadic sexual desire. Overall sexual desire also varied significantly with differences in educational qualifications $(\mathrm{p}<0.05)$ - overall sexual desire was more among those who were educated up to the 12th standard and above. There was no significant difference with regards to other variables.

Table 1. Sexual desire inventory

\begin{tabular}{|l|c|c|c|}
\hline \multirow{2}{*}{ Domain } & Category & $\mathrm{N}=54$ & $\%$ \\
\hline \multirow{2}{*}{ Dyadic sexual desire } & Moderate dyadic sexual desire & 35 & 64.8 \\
\cline { 2 - 3 } & Strong dyadic sexual desire & 19 & 35.2 \\
\hline \multirow{2}{*}{ Solitary sexual desire } & Moderate desire to solitary sexual engagement & 47 & 87 \\
\cline { 2 - 3 } & Strong desire to solitary sexual engagement & 7 & 13 \\
\hline \multirow{2}{*}{ Overall sexual desire } & Moderate sexual desire & 53 & 98.1 \\
\cline { 2 - 3 } & Strong sexual desire & 1 & 1.9 \\
\hline
\end{tabular}




\section{Table 2. Brief sexual function inventory}

\begin{tabular}{|c|c|c|c|}
\hline Domain & Category & $N=54$ & $\%$ \\
\hline \multirow{8}{*}{ Sexual drive } & \multicolumn{3}{|c|}{ No. of days of sexual drive in the past 30 days } \\
\hline & Only a few days & 6 & 11.1 \\
\hline & Some days & 31 & 57.4 \\
\hline & Most of the days & 17 & 31.5 \\
\hline & \multicolumn{3}{|l|}{ Level of sexual drive } \\
\hline & Low & 1 & 1.9 \\
\hline & Medium & 31 & 57.4 \\
\hline & Medium high & 22 & 40.7 \\
\hline \multirow{4}{*}{ Erection } & Erection occurs a few times & 1 & 1.9 \\
\hline & Erection occurs fairly often & 26 & 48.1 \\
\hline & Erection occurs usually & 26 & 48.1 \\
\hline & No problem - good erection & 1 & 1.9 \\
\hline \multirow{3}{*}{ Ejaculation } & Moderate problem & 29 & 53.7 \\
\hline & Mild problem & 24 & 44.4 \\
\hline & No problem in ejaculation & 1 & 1.9 \\
\hline \multirow{3}{*}{ Problem assessment } & Severe problem & 4 & 7.4 \\
\hline & Moderate problem & 23 & 42.6 \\
\hline & Mild problem & 27 & 50 \\
\hline \multirow{3}{*}{ Functional assessment } & Medium function & 4 & 7.4 \\
\hline & Medium high function & 34 & 63 \\
\hline & No problem - good sexual function & 16 & 29.6 \\
\hline \multirow{4}{*}{ Overall satisfaction } & Mostly dissatisfied & 1 & 1.9 \\
\hline & Neutral or mixed & 26 & 48.1 \\
\hline & Mostly satisfied & 21 & 38.9 \\
\hline & Very much satisfied & 6 & 11.1 \\
\hline \multirow{3}{*}{ Total BSFI classification } & Moderate sexual function problem & 19 & 35.2 \\
\hline & Mild sexual function problem & 25 & 46.3 \\
\hline & No problem - good sexual function & 10 & 18.5 \\
\hline
\end{tabular}


Table 3. Associations between sexual desire, function and overall wellbeing, and educational qualifications of the respondents

\begin{tabular}{|c|c|c|c|c|c|c|c|}
\hline Domain & Category & $N=54$ & Mean & SD & $d f$ & $\mathrm{~F}$ & $P$ \\
\hline Dyadic sexual desire & $\begin{array}{l}\text { Illiterate } \\
\text { PUC } \\
\text { UG } \\
\text { PG }\end{array}$ & $\begin{array}{l}5 \\
7 \\
20 \\
22\end{array}$ & $\begin{array}{l}35.60 \\
41.00 \\
40.00 \\
41.86\end{array}$ & $\begin{array}{l}1.82 \\
3.37 \\
3.61 \\
4.45\end{array}$ & 3 & 3.747 & $.017^{*}$ \\
\hline Solitary sexual desire & $\begin{array}{l}\text { Illiterate } \\
\text { PUC } \\
\text { UG } \\
\text { PG }\end{array}$ & $\begin{array}{l}5 \\
7 \\
20 \\
22\end{array}$ & $\begin{array}{l}13.00 \\
15.14 \\
13.45 \\
13.64\end{array}$ & $\begin{array}{l}.71 \\
2.48 \\
2.42 \\
1.65\end{array}$ & 3 & 1.479 & $.231 \mathrm{NS}$ \\
\hline Overall Sexual desire & $\begin{array}{l}\text { Illiterate } \\
\text { PUC } \\
\text { UG } \\
\text { PG }\end{array}$ & $\begin{array}{l}5 \\
7 \\
20 \\
22\end{array}$ & $\begin{array}{l}55.00 \\
65.28 \\
60.55 \\
62.91\end{array}$ & $\begin{array}{l}2.551 \\
8.16 \\
6.50 \\
6.44\end{array}$ & 3 & 2.957 & $.041^{*}$ \\
\hline Erection & $\begin{array}{l}\text { Illiterate } \\
\text { PUC } \\
\text { UG } \\
\text { PG }\end{array}$ & $\begin{array}{l}5 \\
7 \\
20 \\
22\end{array}$ & $\begin{array}{l}6.00 \\
6.43 \\
6.60 \\
7.10\end{array}$ & $\begin{array}{l}1.00 \\
.97 \\
1.79 \\
1.92\end{array}$ & 3 & .730 & $.539 \mathrm{NS}$ \\
\hline Ejaculation & $\begin{array}{l}\text { Illiterate } \\
\text { PUC } \\
\text { UG } \\
\text { PG }\end{array}$ & $\begin{array}{l}5 \\
7 \\
20 \\
22\end{array}$ & $\begin{array}{l}4.20 \\
4.71 \\
4.60 \\
4.95\end{array}$ & $\begin{array}{l}.45 \\
.75 \\
.82 \\
1\end{array}$ & 3 & 1.251 & $.301 \mathrm{NS}$ \\
\hline Problem assessment & $\begin{array}{l}\text { Illiterate } \\
\text { PUC } \\
\text { UG } \\
\text { PG }\end{array}$ & $\begin{array}{l}5 \\
7 \\
20 \\
22\end{array}$ & $\begin{array}{l}6.40 \\
6.29 \\
6.40 \\
7.04\end{array}$ & $\begin{array}{l}1.52 \\
1.89 \\
1.85 \\
2.08\end{array}$ & 3 & .530 & $.663 \mathrm{NS}$ \\
\hline Functional assessment & $\begin{array}{l}\text { Illiterate } \\
\text { PUC } \\
\text { UG } \\
\text { PG }\end{array}$ & $\begin{array}{l}5 \\
7 \\
20 \\
22\end{array}$ & $\begin{array}{l}4.80 \\
5.28 \\
5.60 \\
5.86\end{array}$ & $\begin{array}{l}.45 \\
.75 \\
1.00 \\
1.17\end{array}$ & 3 & 1.749 & $.169 \mathrm{NS}$ \\
\hline Total BSFI classification & $\begin{array}{l}\text { Illiterate } \\
\text { PUC } \\
\text { UG } \\
\text { PG }\end{array}$ & $\begin{array}{l}5 \\
7 \\
20 \\
22\end{array}$ & $\begin{array}{l}21.40 \\
22.71 \\
23.20 \\
24.95\end{array}$ & $\begin{array}{l}2.07 \\
3.30 \\
5.05 \\
5.82\end{array}$ & 3 & .950 & .424 NS \\
\hline Overall Well-being & $\begin{array}{l}\text { Illiterate } \\
\text { PUC } \\
\text { UG } \\
\text { PG }\end{array}$ & $\begin{array}{l}5 \\
7 \\
20 \\
22\end{array}$ & $\begin{array}{l}15.40 \\
16.57 \\
17.30 \\
17.18\end{array}$ & $\begin{array}{l}3.58 \\
3.26 \\
2.25 \\
2.68\end{array}$ & 3 & .763 & $.520 \mathrm{NS}$ \\
\hline
\end{tabular}

NS=Not significant "significant at 0.05 UG=Under-graduate PG=Post-graduate PUC=Pre-University Course 
The age of the respondents was negatively correlated with overall sexual desire $(r=-0.468, p=0.001)$, total BSFI score $(\mathrm{r}=-0.621, \mathrm{p}=0.001)$ and overall well-being $(\mathrm{r}=-0.377$, $\mathrm{p}=0.05$ ) - indicating that sexual desire, sexual functioning and overall well-being decreased with increasing age. Overall well-being was positively correlated with overall sexual desire $(\mathrm{r}=0.407, \mathrm{p}=0.002)$ and total BFSI score $(r=0.455, p=0.001)$. Overall sexual desire and sexual functioning were positively correlated $(r=0.762$, $\mathrm{p}<0.001)$. Income was not correlated with any of the variables.

\section{Discussion}

We found that a majority of our study population had a strong or moderate sexual desire, good sexual satisfaction and mild or moderate sexual function problems. This study adds to the limited data in this field, from India and South Asia. Epidemiologic data are relatively scant for comparison, but Kaminetsky has suggested that these findings are within the normal range (10). We found that $13 \%$ had a strong desire to engage in solitary sexual behaviour (11). This is of importance, since desire to engage in solitary sexual activity may negatively effect the quality of a marital relationship. Exactly half of our study population reported adequate sexual satisfaction. This is lower than the reported sexual satisfaction among university students in USA (84\%), but higher than the rates of satisfaction reported among the older community in the UK $(42 \%)(12,13)$. It is concerning to note that $81 \%$ of our study population reported a sexual dysfunction, although most were mild in nature. The Massachusetts Male Aging Study reported that 52\% of 40-70-year-old men suffer from some form of sexual dysfunction (14). A similar prevalence of sexual dysfunction (49\%) was reported in a study conducted in the older population in rural South India (15). Differences in the prevalence could partly be explained by methodological differences between studies. However, a much higher prevalence of sexual dysfunction in a relatively young population is a cause for concern. This may highlight the need for increased awareness in this population of sexual problems and available treatment options.

This study found a significant positive relationship between sexual desire, sexual function and general wellbeing of a person. This is not surprising, as good physical and psychological health are important for in any sexual activity $(1,16)$. Many health conditions can negatively impact sexual functioning including anxiety, depression, diabetes, kidney or liver failure, heart and vascular diseases (16). The present study found that age is an important factor that negatively impacts interest in sexual activities among males, and this has been reported in previous studies as well $(10,14)$.

\section{Limitations}

The respondents of this study were married males in the city of Kalaburagi. Moreover, this study was conducted in an urban settings. Hence, the results may not be generalizable to other areas, and particularly may not be applicable to rural populations. The sexual desire inventory tool was not validated for use in India, which is another limitation. The small sample size was also one of the limitations. Only about $50 \%$ of the approached sample consented to participate in the study, which may have caused a bias in the results.

\section{Conclusions}

Sexual dysfunction is a common problem among Indian males. Increase in awareness about these problems may encourage people to seek treatment for these important health issues.

Govindappa Lakshmana, Central University of Karnataka, India

Firoz Mohd, National Institute of Mental Health and Neuro-sciences, Bengaluru, Karnataka, India

Alaka Bhargabi Pandaran, Central University of Karnataka, India

Corresponding author: Govindappa Lakshmana

Email: lakshmanagsagar@gmail.com

http://orcid.org/0000-0002-1324-5387

\section{Conflicts of interest}

None declared.

\section{References}

1. Dewitte M, Mayer A.Exploring the Link Between Daily Relationship Quality, Sexual Desire, and Sexual Activity in Couples. Arch Sex Behav. 2018; 47(6):1675-86.

2. Rösing D, Klebingat KJ, Berberich HJ, Bosinski HA, Loewit K, Beier KM. Male sexual dysfunction: diagnosis and treatment from a sexological and interdisciplinary perspective. Dtsch Arztebl Int. 2009;106(50): 821-8.

3. Chandramouli C, General R. Census of India 2011 [Internet]. Provisional Population Totals. New Delhi: Government of India [Cited 28 October 2018]. Available from http://www.censusindia.gov.in/2011-provresults/ paper2/data_files/india/paper2_1.pdf.

4. Spector IP, Carey MP, Steinberg L. The Sexual Desire Inventory: Development, factor structure, and evidence of reliability. J Sex Marital Ther. 1996; 22(3): 175-90.

5. O'Leary MP, Fowler FJ, Lenderking WR, Barber B, Sagnier PP, Guess HA, Barry MJ. A brief male sexual function inventory for urology. Urology. 1995; 46(5): 697-706.

6. Ramdurg S, Ambekar A, Lal R. Co-relationship between sexual dysfunction and high-risk sexual behavior in patients receiving buprenorphine and naltrexone maintenance therapy for opioid dependence. Ind Psychiatry J 2015; 24: 29-34. 
7. Ramdurg S, Ambekar A, Lal R. Sexual dysfunction among male patients receiving buprenorphine and naltrexone maintenance therapy for opioid dependence. J Sex Med. 2012; 9(12): 3198-204.

8. Saha A. Prevalence of sexual dysfunction in cases of alcohol dependence syndrome. Int J Adv Med. 2015; 2: 110-9.

9. Verma SK, Verma A. Manual for PGI general well-being measure. Lucknow: Ankur Psychological Agency; 1989.

10. Kaminetsky J. Epidemiology and pathophysiology of male sexual dysfunction. Int J Impot Res. 2008; 20(1): S3-10.

11. Manuela Peixoto M. Sexual Satisfaction, Solitary, and Dyadic Sexual Desire in Men According to Sexual Orientation. J Homosex. 2019; 66(6): 769-79.

12. Higgins JA, Mullinax M, Trussell J, Davidson JK Sr, Moore NB. Sexual satisfaction and sexual health among university students in the United States. Am J Public Health. 2011; 101(9): 1643-54.
13. Erens B, Mitchell KR, Gibson L, Datta J, Lewis R, Field $\mathrm{N}$, Wellings $\mathrm{K}$. Health status, sexual activity and satisfaction among older people in Britain: A mixed methods study. PLoS One. 2019; 14(3): e0213835.

14. Feldman HA, Goldstein I, Hatzichristou DG, Krane RJ, McKinlay JB. Impotence and its medical and psychosocial correlates: results of the Massachusetts Male Aging Study. J Urol. 1994; 151(1): 54-61.

15. Sathyanarayana Rao TS, Ismail S, Darshan MS, Tandon A. Sexual disorders among elderly: An epidemiological study in South Indian rural population. Indian J Psychiatry 2015; 57: 23641.

16. McCabe MP, Sharlip ID, Lewis R, Atalla E, Balon R, Fisher AD, Laumann E, Lee SW, Segraves RT. Incidence and Prevalence of Sexual Dysfunction in Women and Men: A Consensus Statement from the Fourth International Consultation on Sexual Medicine 2015. J Sex Med. 2016 Feb;13(2):144-52. doi: 10.1016/j.jsxm.2015.12.034. 